\title{
COMMUNITY PREFERENCES, INSURGENCY, AND THE SUCCESS OF RECONSTRUCTION SPENDING
}

\author{
David Scoones \\ Department of Economics, University of Victoria \\ Victoria, B.C., Canada V8W 2 Y2 \\ \& \\ Travers Barclay Child \\ Tinbergen Institute, University of Amsterdam \\ Amsterdam, The Netherlands
}

August, 2012

\begin{abstract}
A model of reconstruction spending by an occupying force is developed, in which the local population may have different preferences over the allocation of spending than the occupier. When the spendingallocation is misaligned with local preferences an insurgency among some members of the community may result. Depending on the effectiveness of the insurgency, local opposition may constrain the abilityof the occupier to implement its most preferred spending allocation. In equilibrium, the occupier may tolerate some level of insurgency to approach its ideal, but naive insistence on a most preferred allocation may lead to fewer projects of any kind being completed. The model suggests that winning the hearts and minds of a local population is less a question of how much money in invested in reconstruction than of how that money is allocated across projects of different kinds.
\end{abstract}

Keywords: Development and Insurgency, Conflict

JEL Classifications: H56, O38, N4

\section{Author Contact:}

David Scoones, Dept. of Economics, University of Victoria, P.O. Box 1700, STN CSC, Victoria, B.C., Canada V8W 2Y2; e-mail: scoones@uvic.ca; ; Voice: (250) 721-8531; FAX: (250) 721-6214 
More than a decade has passed since the 'War on Terror' began with the invasion of Afghanistan in October, 2001. The occupation of Iraq followed in March, 2003, ending eight years later in December, 2011. Major reconstruction efforts have been a central feature of the operations which ensued in both Afghanistan and Iraq, yet the impact of this economic intervention remains scarcely explored. The recent UN-sanctioned military support in the ouster of Libya's former government practically guarantees foreign involvement in Libya's post-war economic recovery, but the relationship between reconstruction work and 'terror' is not clear cut.. At face value, attacks on coalition forces have exhibited an accompanying rise with the upward trend in the volume of reconstruction work carried out in Iraq and Afghanistan. ${ }^{1}$ There exists a prevailing view on reconstruction work, however, as a mitigating force on violence.

Economic reconstruction is thought to facilitate stabilization through the development of a well-functioning market economy. ${ }^{2}$ By providing attractive incentives in the form of economic growth opportunities, coalition forces have sought to win over the 'hearts and minds' of the community in the fight against insurgents. The reconstruction effort has therefore been geared towards rebuilding vital infrastructure and remodeling state institutions for the purpose of enhancing the potential for economic growth and development. While these ingredients may well prove to build economic capacity within a nation, it remains unclear whether economic capacity, built in this way,

\footnotetext{
${ }^{1}$ US government outlays for reconstruction projects in both countries were increasing from 2003 to 2007 as evidenced by data obtained from the Federal Procurement Data System in 2007. Similarly, data obtained from NATO C3 Agency's Afghanistan Country Stability Picture indicates a consistent increase in outlays to Afghanistan over the period for which data is available (approximately 2005 to 2009). Data from the Global Terrorism Database (GTD) of the National Consortium for the Study of Terrorism and Responses to Terrorism (START) at the University of Maryland indicates a consistent upward trend in violence from the beginning of each respective operation until 2010 (the final year for which GTD data is available).

${ }^{2}$ The role of reconstruction in counterinsurgency was explicitly incorporated in the US Army Field Manual 3-24 (US Army, 2006).
} 
translates into stabilization.

This paper constructs a simple model to examine how community preferences interact with the objectives of external forces to create situations of persistent insurrection. The key feature of the model is a distinction between types of reconstructions spending. Not all spending is equivalent in the view of the model's potential insurgents. Depending on how mismatched with preferences of potential insurgents are the objectives of occupiers, and how significantly insurgents can affect the process of reconstruction, it may be that occupiers choose equilibrium spending patterns that engender resistance. This occurs when the alternative, winning the hearts and minds of all potential insurgents, is too costly of a trade off for the occupier.

A large literature on counterinsurgency in both academia and policy circles implicitly assumes that any development is $\operatorname{good}^{3}$, but it appears that neither insurgents nor their supporters agree. The Iraqi population, for its part, expressed in 2006 (WPO) a $32 \%$ disapproval rate regarding US help to Iraqis in organizing their communities to address local needs such as building schools and health clinics. The same survey reported a $27 \%$ rate of strong support for attacks against US-led forces. A slightly larger $41 \%$ of the population indicated a principled approval of US involvement, coupled with reservations regarding how the task was being carried out. Less pronounced support for attacks on US-led forces registered at a rate of $34 \%$. There is a striking similarity between the disapproval rate for reconstruction work and the approval rate for attacks on coalition forces. ${ }^{4}$

A careful reading of intercepted correspondence between al Qaeda mem-

\footnotetext{
3The terms 'development' and 'reconstruction work' are used more or less interchangeably throughout this paper given that the distinction between the two is negligible in practice. That is, reconstruction work need not imply the re-construction of a particular institution which existed in the past. Rather, the majority of the reconstruction effort is comprised of new developments.

${ }^{4}$ Moreover, $94 \%$ of the population was found to hold an unfavourable view of al Qaeda, suggesting even further that community support for the insurgency in Iraq is linked more to real-time activities of the occupation forces than the inherent religious or ideological fanaticism which is often alluded to in the literature.
} 
bers further reveals the connection between insurgency and economic discontent. Bin Laden writes of 'wealth and assets [being] looted by the hands of the enemies' (CTC, 2007c, p.1). He speaks of 'suffering, bitter suppression, subjugation, excessive injustice, degrading oppression and poverty... deterioration of the economy, inflation, high cost of living, [and] ever-increasing debts' (p.2) in his call for resistance to Muslim peoples. Sensitivity to foreign involvement in the oil industry is evident in these documents (CTC, 2007c; CTC, 2006), as is sensitivity to restructuring education along Western lines, and the promotion of Western media as discussed by al Zawahiri (CTC, 2007b). Another document (CTC, 2007a) reveals how one high-ranking western-educated insurgent decided to join al Qaeda in a bid to oppose the Western-imposed development that, in his view, has led to the deterioration of Muslim nations. It would seem then, that economic considerations factor not only into the calculation of support for insurgency, but also into the decision regarding participation.

If support for an insurgency is driven by disapproval of reconstruction activities, and if participation in the insurgency is driven by discontent with economic developments (of which the reconstruction effort forms a considerable share), then it directly follows that a well-received reconstruction effort should decrease both the support and membership base of the insurgency. In fact, where Iraqi citizens comprised 90\% of the insurgency in Iraq in 2005 (Baker, 2005), support and participation might best be thought of as varying degrees of the same sentiment which may or may not be present in each member of the community. A well designed reconstruction effort should then have the effect of depressing that sentiment within the local populace, while introducing a commensurate augmentation of the reverse sentiment - approval of the occupation. ${ }^{5}$ That said, the question remains: what constitutes a well designed reconstruction effort?

The model developed here suggests the reconstruction effort has the po-

\footnotetext{
${ }^{5}$ To be sure, the term occupation is meant to be normatively neutral here, and throughout the remainder of this paper.
} 
tential to either strengthen the insurgency or, contrarily, increase local cooperation with the occupier. The greater reconstruction effort is comprised of work carried out in a number of sectors including for example agriculture, health, education, and transport. We postulate that local communities welcome the involvement of coalition forces in some sectors of the economy, but oppose it in other, more controversial sectors. Depending on its structure, the overall reconstruction effort could be met with approval or disapproval. Assuming community members oppose coalition involvement in controversial sectors to varying degrees, we expect a given reconstruction effort to produce a range of reactions in the community regarding the approval of the occupation. We assume the rate of opposition to the occupation to directly affect the level of insurgency that ensues in the country.

If the level of insurgency is determined by the character of the reconstruction effort and the occupier can alter the level of insurgency through reallocation of reconstruction work across sectors, why should there exist an insurgency at all? Why would occupiers not choose spending allocations that totally placate the local population? The simple answer is that occupiers are occupiers for a reason: if the local political preferences were such that local development occurred in a way favoured by the occupiers, the only thing required for further development would be financial support. The occupier has its own aims regarding the ideal structure of reconstruction spending, however, and the difference between the occupier's aims and community preferences creates a tradeoff between spending efficiency (insofar as insurgency decreases reconstruction output) and allocative efficiency across reconstruction sectors. Depending on how starkly community and occupier preferences differ, the occupier's ideal spending strategy may well produce an insurgency in equilibrium.

The model here is distinguished from previous literature in part by its treatment of the motivation of three agents: insurgents, community, and government/occupier. Typically, the existing literature treats insurgents as being motivated by a thirst for power, by economic deprivation, or by a zeal 
for violence for its own sake. Where insurgents seek power they conduct violence with the ultimate aim of gaining political leverage over either the government (e.g. Bueno de Mesquita, 2005a, Crost and Johnston, 2010) or competing rebel groups (as in Bueno de Mesquita and Dickson, 2007). Where insurgents have been economically deprived they operate in order to gain material wealth. For Fearon (2008), Bueno de Mesquita (2005b), and Siqueira and Sandler (2006), this material wealth has taken some form of rents. Berman (2003) and Berman and Laitin (2005; 2008) have proposed rebel 'club' goods ${ }^{6}$ as the driving incentive for violence. Blomberg, Hess, and Weerapana (2004) have modeled this material reward in the form of economically preferential policy. Where insurgents have been motivated by violence per se, it is the very act of violence which makes them (somehow) better off, as modeled by Siqueira and Sandler (2006) and Berman, Shapiro, and Felter (2009). Similarly, Bueno de Mesquita (2005b) posits an exogenously determined ideological component in insurgent preferences which is addressed but never satisfied through the conduct of violence and so is perpetual in nature. Our model differs from all of the above in that it allows insurgents to embody a truly political purpose, where insurgency is not presupposed but rather is contingent upon politically controversial actions of the occupier.

The existing literature has typically afforded the community a very narrow role. The community is not acknowledged in Bueno de Mesquita (2005a), Berman (2003), or Berman and Laitin (2005; 2008). Bueno de Mesquita and Dickson (2007) acknowledge the community but afford it the status of an observer left to support one of two rebel factions. The community chooses to support either the government or the rebels in Siqueira and Sandler (2006) and Berman, Shapiro, and Felter (2009). In our model, the community is not a separate type of agent at all, but is rather the source of insurgents.

Finally, in existing models of insurgency, the occupier is granted a benevolent purpose, but not examined in detail. Bueno de Mesquita (2005a), Bueno

\footnotetext{
${ }^{6}$ These 'club' goods, from Iannaccone (1992), are essentially public goods offered only to those within the rebel organization.
} 
de Mesquita and Dickson (2007), and Siqueira and Sandler (2006) treat the defeat of terrorists as the government's aim. In other modeling designs, the government exists to minimize violence - an approach adopted by Bueno de Mesquita (2005b), Berman (2003), Berman and Laitin (2005; 2008), and Berman, Shapiro, and Felter (2009). This framework is problematic in that insurgents are then the agents of violence, and government the agent of peace. Any violence in equilibrium stems from a budgetary constraint suffered by government rather than the choices it makes. By contrast, in our model the occupier has economic or political goals unrelated to insurgency, which can nevertheless interact with the state of resistance in either a positive or negative way to ameliorate or aggravate the insurgency.

Based on the above assumptions about agent motives, the existing literature dichotomizes policy instruments into hard and soft counterinsurgency. Hard counterinsurgency is one means through which governments are expected to mitigate the level of violence in a society. This tactic here refers to offensive military operations against insurgents, and the defensive hardening of targets, carried out for the purpose of rendering insurgent activity more risky and less fruitful (for example, Bueno de Mesquita and Dickson, 2007; Bueno de Mesquita, 2005b; Siqueira and Sandler, 2006; and Berman, Shapiro, and Felter, 2009). Soft counterinsurgency in contrast operates on the incentives to participate in an insurgency. By improving local economic conditions through either public goods provision or better market opportunities, the marginal benefit and opportunity cost drawn from insurgent activity is expected to decline and increase, respectively. Public goods are stressed by Bueno de Mesquita (2005a), Siqueira and Sandler (2006), Frey and Luechinger (2002), Berman (2003), Berman and Laitin (2005; 2008), and Berman, Shapiro, and Felter (2009). Bueno de Mesquita (2005a), Frey and Luechinger (2002), Berman (2003), and Berman and Laitin (2005; 2008) propose enhancing market opportunities as a means of alleviating violence.

Thus the literature recommends a pair of possible solutions to the problem of counterinsurgency. Wherever insurgents operate to maximize economic 
wealth, they can be bought out (through soft counterinsurgency measures). Otherwise, insurgents cannot be dissuaded from conducting violence (it is hardwired into their purpose of existence) and so the only feasible strategy is hard counterinsurgency. Together, these two strategies leave little room for adaptation or political compromise.

The model in this paper focuses on the nature of soft counterinsurgency. Insurgents do not resist because of poverty, desire for control, or love of violence, but for ideology - their view about what exactly constitutes reconstruction. Nevertheless, soft counterinsurgency can still be effective, at the cost of not achieving the ideal outcome in the eyes of the government.

\section{The model}

Reconstruction and insurgency is a one shot game played between two types of agents: a single occupier, and a continuum of community members, normalized to a unit measure population. All possible reconstruction projects fall into one of two 'sectors', $g$ and $b$. The occupier seeks to maximize utility through its allocation of a fixed amount of reconstruction spending across these two sectors. Each community member either joins the insurgency or co-operates with the occupier, depending on their relative distaste for the mix of reconstruction projects chosen by the occupier. The occupier moves first in anticipation of the reaction of the community; individual community members then choose whether or not to resist reconstruction. The combination of occupier spending and community resistance determines the level of reconstruction and payoffs, and the game ends.

\section{$1.1 \quad$ Preferences}

The occupier has Cobb-Douglas preferences over reconstruction in the two sectors:

$$
V=g b^{\gamma}
$$


where $\gamma$ captures the occupier's relative preference for reconstruction type $b$ over type $g$. The preferences of community member $i$ is represented by

$$
U_{i}=\alpha g-\beta_{i} b
$$

where $\alpha$ is the common preference for sector $g$ output, $0 \leq \alpha \leq 1$, and $\beta_{i}$ captures individual $i$ 's distaste for sector $b$ output. Formally, we assume that $\beta_{i}$ is uniformly distributed on the unit interval, but the model can easily account for situations in which a section of the population is in permanent resistance. $^{7}$

The notation $g$ and $b$ is used as a shorthand for 'good' and 'bad' respectively in accordance with the community's perception of the reconstruction effort and the occupation at large. To be sure, we do not assume community members dislike projects in sector $b$ per se. Instead, these projects are unwelcome specifically because the work is undertaken by an occupying force. Intuitively, building prisons might fall into sector $b$. This wouldn't imply the community prefers to have no prisons, but rather that it would prefer not to have an occupying force ${ }^{8}$ implicated in their construction and administration. On the other hand, the maintenance of hospitals would more intuitively settle in sector $g$. That is, even the views of those most predisposed to oppose the reconstruction effort are likely to be softened by humanitarian work of the occupier.

\footnotetext{
${ }^{7} \mathrm{~A}$ fixed insurgency decreases the utility payoff of the occupier and renders community resistance more damaging, but the game between occupier and community remains essentially the same.

${ }^{8}$ The controversial 'occupier' here includes private contractors in addition to military personnel. Projects implemented by members of the local population are less relevant to this framework, but project choice and design by an occupier can nevertheless render them subject to community resistance.
} 


\subsection{Reconstruction technology}

The occupier faces a budget which it can allocate between sector $b$ and sector $g$ spending. 9

$$
E=S_{g}+S_{b}
$$

where $E$ is the occupier's budget, $S_{g}$ is spending in sector $g$ and $S_{b}$ is spending in sector $b$. The production function for the output in each sector takes the form

$$
g=S_{g}(1-R)^{\theta} \quad b=S_{b}(1-R)^{\theta}
$$

where $R \in[0,1]$ is the proportion of the community that chooses to participate in the insurgency and $\theta \in[0,1]$ is a coefficient that captures the character, or effectiveness, of the insurgency.

This effectiveness parameter can be thought of as the propensity of insurgents to conduct violence as opposed to other, less destructive, means of resistance. Formal political activity, strikes, and mass demonstrations, for instance, can be considered passive forms of resistance which nevertheless restrict reconstruction output to varying degrees. The effectiveness of the insurgency will also be a function of the intrinsic skill and organizational capabilities of insurgents, and of the occupier's level of spending on hard counterinsurgency. In this model we take effectiveness as parametric to focus on the impact of soft counterinsurgency on community perceptions, rather than a militaristic assessment of insurgency operability.

The equations in (4) assume that insurgency restricts output in both sectors equally. This significantly simplifies the analysis, but can be relaxed while maintaining the model's key results. That is, if the effectiveness of the insurgency is greater in sector $b$, then the occupier's spending allocation is simply tilted more towards sector $g$ in equilibrium. ${ }^{10}$

\footnotetext{
${ }^{9}$ Instead, we could assume that there are convex costs of reconstruction.

${ }^{10}$ See proof in Appendix A.
} 


\section{Equilibrium}

An equilibrium is a utility maximizing choice by the occupier of spending levels in each sector $\left(S_{g}^{*}, S_{b}^{*}\right)$; and a utility maximizing decision by each community member whether to resist reconstruction, characterized by the threshold value $\beta_{i}^{*}$ in the set of insurgents. Community members observe the spending allocation of the occupier before deciding whether to join the resistance; the occupier knows this and chooses an allocation with rational expectations of the coming level of resistance.

There are three exogenous parameters that determine the structure of the equilibrium: $\alpha, \gamma$, and $\theta$. To solve the model we first calculate the response of community members to a given reconstruction spending: this determines $R$ as a function of $\alpha$. Using this and the production functions (4), we compute the "reconstruction possibility set" facing the occupier, which is a function of $\alpha$ and $\theta$. Understanding the structure of this set is the key to understanding the model. Finally, the occupier chooses the optimal spending mix, which depends on the reconstruction possibility set and the value of $\gamma$. Depending on the values of the three key parameters, the equilibria of the model will fall into one of three classes. In general, we can characterize these by fixing two parameters, and varying the third. In keeping with our focus on community preferences, as a rule we will fix $\theta$ and $\gamma$, and discuss the equilibria in terms of different values of $\alpha$.

\section{$2.1 \quad$ Resistance}

Substituting the production functions (4) into the community member utility function in (2), community member's utility can be written as a function of the insurgency's size $R$ :

$$
U_{i}=\alpha S_{g}(1-R)^{\theta}-\beta_{i} S_{b}(1-R)^{\theta}
$$

Community members decide whether to join the insurgency independently, taking $R$ as fixed, and recognize that their choice will contribute 
only infinitesimally to the resistance. Taking the derivative of utility with respect to insurgency size we obtain

$$
\frac{\partial U_{i}}{\partial R}=-\alpha \theta S_{g}(1-R)^{\theta-1}+\beta_{i} \theta S_{b}(1-R)^{\theta-1}
$$

The sign of $\partial U_{i} / \partial R$ indicates whether community member $i$ would perceive himself to be better or worse off with a marginal increase in the size of the insurgency. If $\partial U_{i} / \partial R$ is positive for $i$, then he will choose to join the insurgency; if $\partial U_{i} / \partial R$ is negative, then community member $i$ will cooperate with the occupier. By setting this derivative equal to zero, we can obtain $\beta_{i}^{*}$ - the distaste for sector $b$ spending of the community member who is just indifferent between resisting and cooperating. If no community member is indifferent, then $\beta_{i}^{*}$ takes a value at one of the endpoints of its distribution. Thus,

$$
\beta_{i}^{*}=\min \left\{\frac{\alpha S_{g}}{S_{b}}, 1\right\}
$$

Since the sign of $\partial U_{i} / \partial R$ is monotonically increasing in $\beta_{i}$, all community members with a distaste for sector $b$ output greater than that of the marginal insurgent will join the insurgency. All those who dislike $b$ less than the marginal insurgent will cooperate with the occupier. Given that there is a unit measure of community members, the size of the resistance is $R=1-\beta_{i}^{*}$. Together with (6) this implies that

$$
R=\min \left\{1-\frac{\alpha S_{g}}{S_{b}}, 0\right\}
$$

From equation 7 , it is clear that the size of the insurgency decreases with a relative increase in the expenditure on sector $g$, and increases with a relative increase in the expenditure on sector $b$, provided a state of insurgency is reached. For a given ratio of spending, the insurgency is smaller for greater values of $\alpha$. 


\subsection{Reconstruction possibility set}

The choices of community members whether to resist reconstruction, the production functions for the two sectors and the overall budget constraint together determine the set of feasible reconstruction projects among which the occupier can choose. We denote the boundary of this set $b=P(g)$. The shape of this set depends on the parameters $\alpha$ and $\theta$.

To construct $P$, we first observe that (7) determines a critical ratio of spending on sector $b$ relative to sector $g$ below which no community member joins the insurgency. That is, if $S_{b} \leq \alpha S_{g}$ then $R=0$. We refer to this as the no resistance constraint. ${ }^{11}$ When spending satisfies this constraint the production functions become simply $g=S_{g}$ and $b=S_{b}$, and the no resistance constraint can also be written $b \leq \alpha g .{ }^{12}$ Therefore when the allocation satisfies the no resistance constraint, spending translates directly into output, and the reconstruction possibility set is identical to the budget set. Using the budget constraint, it follows directly that for sector $g$ reconstruction to be consistent with no resistance, $g \geq E /(1+\alpha)$. For values in this range, $P(g)=E-g$, and is independent of $\theta$.

When $g<E /(1+\alpha)$, some members of the community join the insurgency, and the curvature and location of the reconstruction possibility boundary depend on how effective this is, i.e. on $\theta$. In the trivial case where resistance is ineffective, $\theta=0$, and spending again translates directly into output. In this case, for all values of $g, P(g)=E-g$. In particular, $P(0)=E$, even though for this allocation, all community members join the insurgency. In contrast when $\theta>0$, with $S_{g}=0$ and all community members resisting, output in both sectors falls to zero. Thus $P(0)=0$. So the boundary of the reconstruction possibility set at $g=0$ jumps discontinuously from the origin to $(0, E)$ as $\theta \rightarrow 0$.

\footnotetext{
${ }^{11}$ Notice that this is not a true constraint on the occupier: the occupier can choose to spend relatively more on sector $b$ than this, but spending above this level leads to resistance from some community members.

${ }^{12}$ This, of course, can be derived directly from community preferences, which in fact depend on output not spending.
} 
It is also simple to analyse the case of $\theta=1$. For this value, resistance is so effective that reducing spending on $g$ below $g=E /(1+\alpha)$ reduces development in both sectors. This can be observed immediately by substituting (7) and the budget constraint into the production functions, for $\theta=1$ :

$$
b=\alpha\left(E-S_{b}\right) \quad g=\alpha\left(E-S_{b}\right)^{2} / S_{b}
$$

Output in both sectors decreases with additional spending in sector $b$ projects.

More generally, for any $\theta>0, P(0)=0$ and $P\left(\frac{E}{1+\alpha}\right)=\frac{\alpha E}{1+\alpha}$, so the boundary of the reconstruction possibility set must somewhere have a positive slope for all $\alpha>0$. Hence increases in $S_{g}$ must over some range increase output in both sectors. When $\theta=1$ we know the frontier increases monotonically in this range, but in general it need not. In Appendix B we show that when the no resistance constraint is breached (that is, when $S_{g}<\frac{E}{1+\alpha}$ ),

$$
P^{\prime}=\frac{-S_{b}}{S_{g}}\left[\frac{(1-\theta) E-S_{b}}{\theta E+S_{b}}\right]
$$

So $P^{\prime}<0$ whenever $S_{b}<(1-\theta) E$. Notice that when $\theta=0, P^{\prime}=-1$ as expected. But in general for $\theta>0, S_{g}<E /(1+\alpha), P^{\prime} \in(-1, \infty)$. An example of a non-monotonic reconstruction possibility frontier is illustrated in Figure 1. In this figure, $\alpha=0.5$ and $\theta=0.2$.

In what follows, we are particularly interested in the left hand limit of $P^{\prime}$ at the intersection with the no resistance constraint, $\lim _{S_{g} \rightarrow\left(\frac{E}{1+\alpha}\right)^{-}} P^{\prime}\left(S_{g}\right)$. Recall that at this point, $b=S_{b}, g=E-S_{b}$, and $b=\alpha g$. Substituting these equations into the expression for $P^{\prime}$ implies that

$$
\lim _{S_{g} \rightarrow\left(\frac{E}{1+\alpha}\right)^{-}} P^{\prime}\left(S_{g}\right)=-\alpha\left[\frac{1-(1+\alpha) \theta}{\theta+(1+\theta) \alpha}\right]
$$

Notice that for $\theta>0$, the left hand limit of $P^{\prime}$ is greater than -1 . Since the right hand limit of the derivative at this point is always -1 , in general $P$ is not differentiable at $g=\frac{E}{1+\alpha}$. 


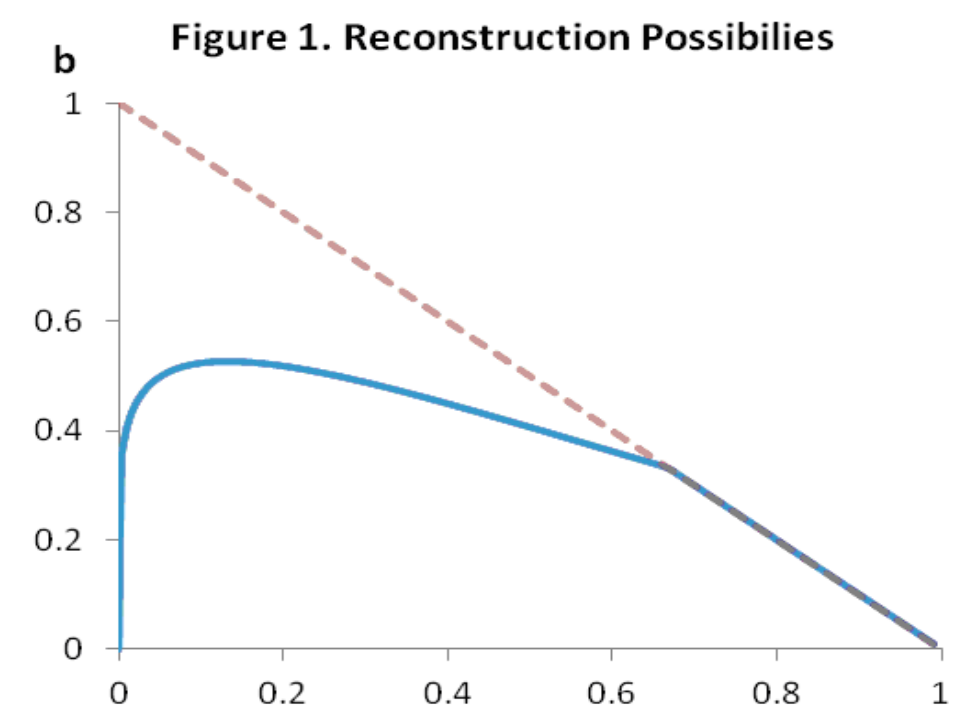

\section{$2.3 \quad$ Project choice}

We now can calculate the occupier's optimal allocation of reconstruction spending. As mentioned above, the solutions divide into three classes. In this section we describe these more precisely and in the next section discuss their interpretation. In the first class of equilibria, $\alpha$ is large (relative to $\gamma$ ). In this case, the no resistance constraint is steep, and the optimal mix of projects lies in the region where $b<\alpha g$. We refer to this as a situation of no resistance. In the second class, $\alpha$ is smaller and resistance occurs, but the no resistance constraint does not bind. If $\theta$ is sufficiently small, even though resistance reduces overall reconstruction, it does so insufficiently to deter the occupier from choosing $b>\alpha g$, in effect violating the no resistance constraint. We refer to this as a situation with an active resistance. In the third class, $\alpha$ is again small but $\theta$ is larger, so resistance is effective, frustrating the occupier's desire to increase spending in sector $b$. Here the no resistance constraint binds, and we refer to a situation with a latent resistance.

\section{Class 1: no resistance}

Assume that the no resistance constraint does not bind, i.e. $b<\alpha g$. Then the 
production functions are simply $b=S_{b}$ and $g=S_{g}$. Substituting these into its objective function, the occupier must solve the following simple problem.

$$
\max _{S_{g}, S_{b}} V=\ln S_{g}+\gamma \ln S_{b} \quad \text { s.t. } E=S_{g}+S_{b}
$$

The solution is $g^{*}=S_{g}^{*}=E /(1+\gamma)$ and $b^{*}=S_{b}^{*}=E \gamma /(1+\gamma)$, so $b^{*}=\gamma g^{*}$. Clearly, this is a solution if and only if $\alpha>\gamma$, and this condition is therefore necessary and sufficient for the equilibrium to be in class 1 .

\section{Class 2: active resistance}

Now assume that $\alpha<\gamma$, and furthermore there is an active resistance, i.e. $b>\alpha g$. Substituting in the production functions (4) and the equation for insurgency (7), into its objective function, the occupier's problem becomes

$$
\max _{S_{g}, S_{b}} V=\ln \left[S_{g}\left(\frac{\alpha S_{g}}{S_{b}}\right)^{\theta}\right]+\gamma \ln \left[S_{b}\left(\frac{\alpha S_{g}}{S_{b}}\right)^{\theta}\right] \quad \text { s.t. } E=S_{g}+S_{b}
$$

The first order conditions yield

$$
S_{b}^{*}=E\left[\frac{\gamma}{1+\gamma}-\theta\right] \quad S_{g}^{*}=E-E\left[\frac{\gamma}{1+\gamma}-\theta\right]
$$

Notice that with an active resistance, the spending allocation is independent of $\alpha$. This is an artifact of the functional forms we have chosen, and not a general property. The term within the square brackets in (10) is the share of the budget allocated to spending on the public bad. From (10),

$$
\frac{b^{*}}{g^{*}}=\frac{S_{b}^{*}}{S_{g}^{*}}=\frac{\gamma-\theta(1+\gamma)}{1+\theta(1+\gamma)} \leq \gamma
$$

Notice that, holding $\alpha$ and $\gamma$ fixed, as $\theta \rightarrow 0$ and the insurgency becomes completely ineffective, $S_{b}^{*} / S_{b}^{*} \rightarrow \gamma$, as expected from our class 1 equilibrium.

By construction, the solution in (10) requires that the occupier's indifference curve be tangent to the reconstruction possibility frontier at some point where $b>\alpha g$. A necessary condition for this is that the left hand limit 
of $P^{\prime}\left(\frac{E}{1+\alpha}\right)$ is less than the occupier's marginal rate of substitution at the intersection of $P$ and the no resistance constraint.

Straightforward computation yields $M R S(g, \alpha g)=-\alpha / \gamma$. Using (9), the necessary condition for the solution to be in class 2 is that

$$
\alpha<\frac{\gamma-(1+\gamma) \theta}{1+(1+\gamma) \theta}
$$

\section{Class 3: latent resistance}

As we have seen, in general $P$ is not differentiable at $b=\alpha g$, and may be upward sloping to the left of this point. So there is no guarantee that condition (11) holds. In general, there is a set of values of $\alpha$ for which

$$
\gamma>\alpha>\frac{\gamma-(1+\gamma) \theta}{1+(1+\gamma) \theta}
$$

For these values, the solution is at the intersection of the no resistance constraint and the reconstruction possibility set: $S_{g}^{*}=\frac{E}{1+\alpha}$ and $S_{b}^{*}=\frac{\alpha E}{1+\alpha}$.

\section{Discussion}

Which of the model's three classes of equilibria obtains depends on the occupier's willingness to trade off a larger share of sector $b$ output against lower production overall. The three classes can be characterized by the occupier's marginal rate of substitution evaluated at the point $b=\alpha g$, and is captured by the pair of inequalities in (12).

In class 1 , when $\alpha>\gamma$ the occupier prefers a mix of spending that respects the no resistance constraint. Intuitively, the community likes sector $g$ output relatively more than the occupier likes sector $b$ output. We interpret this to be the case where occupier's values are well aligned with the community, so there is no resistance to reconstruction. This is in some sense the best that can be hoped for, given the fundamental disagreement over the value of sector $b$ reconstruction. It is how the model would capture foreign development aid more generally in situations where local resistance does not present any 
difficulties. Note that this outcome requires sufficient, but not complete agreement on development goals.

Class 2 equilibria describe situations in which reconstruction proceeds in the face of disruption from a local insurgency. The preferences of the occupier and the community are at greater variance, but the effectiveness of the resulting resistance is not sufficient to deter the occupier from inducing an insurgency through its spending choices. A high propensity to resist (low level of $\alpha$ ) is associated with this equilibrium outcome, and the government uses sector $g$ spending as leverage against the community to reduce the level of violence while accepting some resistance in equilibrium. In effect, the insurgency acts as a tax on sector $b$ spending and so shifts spending toward sector $g$, while at the same time, due to the externality it imposes on both sectors, reduces reconstruction overall. Despite the deadweight loss of output, the occupier's preferences are such that its payoff in terms of allocative efficiency offsets the production efficiency loss incurred. The combined effect depends on the disruptive power of the insurgency, and the preferences of the occupier. Holding $\alpha$ and $\gamma$ fixed, as $\theta \rightarrow 0$, the insurgency becomes increasingly ineffective, and the equilibrium spending ratio $S_{b}^{*} / S_{g}^{*} \rightarrow \gamma$. Thus if the effectiveness of the insurgency is very low, the occupier behaves almost as though insurgents do not exist. The occupier chooses a spending allocation close to its most preferred mix of projects, relatively unconstrained by the presence of insurgency. For fixed $\theta$ and $\alpha$, the higher is the occupier's relative preference for sector $b$ output, $\gamma$, the more its equilibrium allocation will generate discontent amongst community members. Hence for small $\theta$ or large $\gamma$, a large insurgency can exist in equilibrium.

Finally, there is a set of equilibria in class 3 with $\alpha$ in an intermediate range. For these, resistance is sufficiently effective to deter the occupier from choosing a spending mix beyond the point that causes any member of the community to join an insurgency. No actual insurgency exists, but the latent threat affects the choice of the occupier. Class 2 and 3 partition the values of $\alpha<\gamma$ with the sizes of the two partitions depending on $\theta$. This is 
immediately apparent from the inequalities in (12). When $\theta=0$, resistance is completely ineffective, the intermediate range of $\alpha$ closes, and class 3 is empty. At the other extreme, when $\theta=1$, resistance is highly effective, and any positive value of $\alpha<\gamma$ yields an equilibrium in class 3, so class 2 is empty.

Equilibria in each of the three classes are illustrated in Figure 2. In this diagram, the only parameter that varies is $\alpha$.

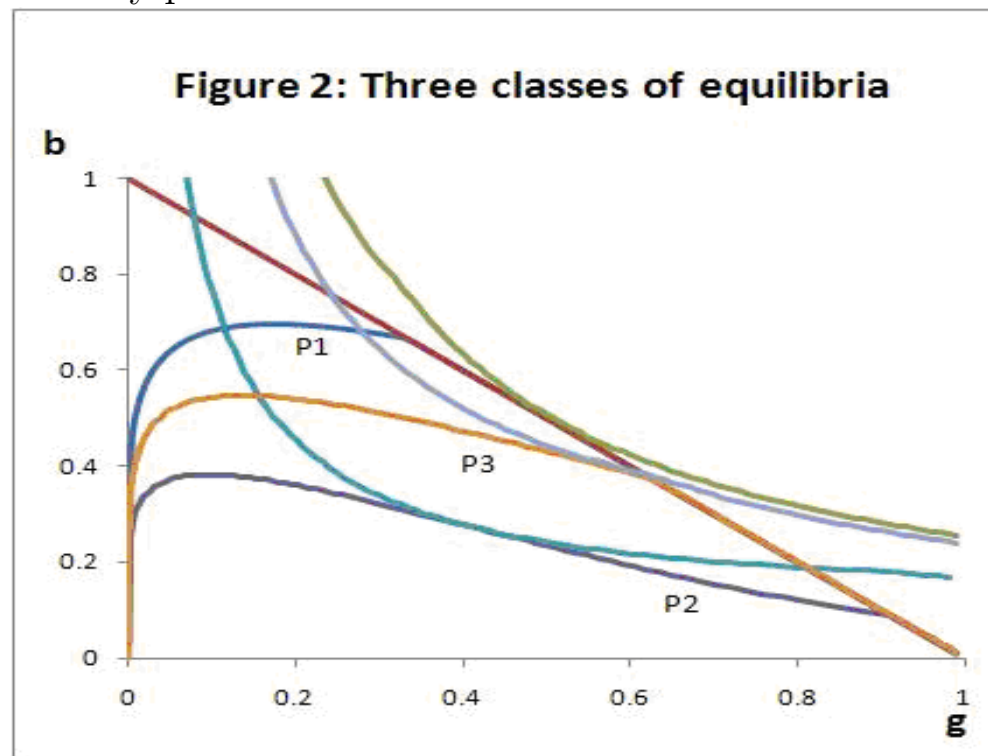

\section{Conclusion}

By drawing a distinction between "good" and "bad" reconstruction, we build a model that shifts focus away from asking the question "how much reconstruction?" to the question "what reconstruction?". The fundamental premise of the model is that reconstruction spending will be viewed differently by the community depending on what exactly is being "reconstructed". In addition to a balance between militaristic strategies and "winning hearts and minds", occupiers must think carefully about what type of reconstruction they wish to engage in. We find that the trade-off demanded by the community to eliminate resistance entirely may very well be too costly in terms of the occupier's objectives. In this case, there is an insurgency in 
equilibrium.

The extent of the insurgency is determined by community perceptions of the reconstruction effort. Reconstruction per se has the potential to either mitigate or exacerbate an insurgency. Spending on projects which are negatively perceived by the community will result in increased hostility and resistance, whereas spending on projects which are welcomed by the community will result in increased community cooperation. Although it is quite intuitive, this proposition has not been developed in previous formal work. This notion also seems to be absent in the literature's explanations regarding failures of the reconstruction effort in establishing peace. Cases where substantial increases in the aggregate level of reconstruction spending have resulted in little variation in community cooperation or insurgency may seem puzzling, but are less enigmatic when the type of spending is considered.

The model suggests some potentially testable propositions. Political, economic, social, and cultural characteristics of a population will factor strongly into community preferences regarding development, and these characteristics can be expected to vary from region to region within a country. If the occupier pursues his ideal spending mix without regard for community preferences, regions in which the community's preferences are more in line with those of the occupier will suffer little disruption relative to regions in which these preferences more strongly differ. It is likely that different ethnic groups within Afghanistan and Iraq for instance, possess different views regarding reconstruction. Insofar as the occupier's spending mix remains constant across the country, one would expect to see different levels of insurgency arising out of different ethnic regions. An important implication is that optimal reconstruction will vary from region to region within the country.

Moreover, where the character of the reconstruction effort varies (in terms of sectoral allocation) throughout a homogenous region, we expect different levels of insurgency to arise in response. Those areas characterized by a high degree of foreign involvement in sensitive sectors will exhibit a higher degree of resistance, while areas enjoying projects more in line with local preferences 
regarding development will be relatively more peaceful. 


\section{Appendix A}

The effectiveness of violence need not be equal across sectors. If the insurgency targets one sector more than the other, the occupier's problem remains essentially the same. We outline the solution only for the case of an active resistance, as this is sufficient to demonstrate the model's robustness to this assumption.

We can redefine the production functions as follows:

$$
g=S_{g}(1-R)^{\theta} \quad b=S_{b}(1-R)^{\phi}
$$

with $\theta \neq \phi$.

We then take the marginal benefit of the community member to an increase in the level of resistance.

$$
\frac{\partial U_{i}}{\partial R}=-\alpha \theta S_{g}(1-R)^{\theta-1}+\beta_{i} \phi S_{b}(1-R)^{\phi-1}
$$

The community's first order condition yields the marginal insurgent

$$
\beta_{i}^{*}=\frac{\alpha S_{g}}{S_{b}} \frac{\theta}{\phi}(1-R)^{\theta-\phi}
$$

Solving $R=1-\beta_{i}^{*}$ for $R$, we obtain

$$
R=1-\left(\alpha \frac{S_{g}}{S_{b}} \frac{\theta}{\phi}\right)^{\frac{1}{1+\phi-\theta}}
$$

Taking into account the budget constraint in (3), the occupier then solves

$$
\begin{aligned}
& \max _{S_{b}}\left(E-S_{b}\right)\left(\alpha \frac{S_{g}}{S_{b}} \frac{\theta}{\phi}\right)^{\frac{\theta}{1+\phi-\theta}} S_{b}^{\gamma}\left(\alpha \frac{S_{g}}{S_{b}} \frac{\theta}{\phi}\right)^{\frac{\phi \gamma}{1+\phi-\theta}} \\
\longrightarrow & \max _{S_{b}}\left(E-S_{b}\right)^{1+\phi+\phi \gamma} S_{b}^{\gamma-\gamma \theta-\theta}\left(\frac{\alpha \theta}{\phi}\right)^{\frac{\theta+\phi \gamma}{1+\phi-\theta}}
\end{aligned}
$$


Finally, the first order condition yields

$$
\begin{aligned}
& S_{b}=E\left[\frac{\gamma-\gamma \theta-\theta}{1+\gamma \phi+\phi+\gamma-\gamma \theta-\theta}\right], \\
& S_{g}=E\left[\frac{1+\gamma \phi+\phi}{1+\gamma \phi+\phi+\gamma-\gamma \theta-\theta}\right]
\end{aligned}
$$

Note that in the special case where $\phi=\theta$, the above solution is equivalent to the Class 2 outcome outlined in the body of the paper. Where $\phi \neq \theta$, however, the more is violence targeted at sector $b$, the greater is the share of spending on sector $g$ (and vice versa). This is an intuitive result which introduces an additional determinant of spending allocation - the differential impact of resistance across sector productivity. 


\section{Appendix B}

Let $b=P(g)$ denote the boundary of the feasible reconstruction choices available to the occupier. To simplify notation, define $S=S_{b}$, so $S_{g}=E-S$, and let $\Phi(S)=\min \left\{\left(\frac{\alpha(E-S)}{S}\right)^{\theta}, 1\right\}$. Then $b=S \Phi$ and $g=(E-S) \Phi$.

When $S>\alpha(E-S), \Phi<1$. Then

$$
P^{\prime}=\frac{\partial b / \partial S}{\partial g / \partial S}=\frac{\Phi+S \Phi^{\prime}}{-\Phi+(E-S) \Phi^{\prime}}=\frac{1+S \Phi^{\prime} / \Phi}{-1+(E-S) \Phi^{\prime} / \Phi}
$$

where $\Phi^{\prime}=\theta\left(\frac{\alpha(E-S)}{S}\right)^{\theta-1}\left(\frac{-\alpha E}{S^{2}}\right)$, so

$$
\frac{\Phi^{\prime}}{\Phi}=\frac{\theta\left(\frac{\alpha(E-S)}{S}\right)^{\theta-1}\left(\frac{-\alpha E}{S^{2}}\right)}{(\alpha(E-S) / S)^{\theta}}=\frac{\theta\left(-\alpha E / S^{2}\right)}{\alpha(E-S) / S}=\frac{-\theta E}{(E-S) S}
$$

Simplifying,

$$
P^{\prime}=\frac{-S}{E-S}\left[\frac{(1-\theta) E-S}{\theta E+S}\right]
$$




\section{References}

Baker, P.H. (August, 2005). Lessons from the January elections. Fund for Peace Iraq Conflict Report 4. Retrieved from

http://www.fundforpeace.org/web/images/pdf/iraq-report04abridged.pdf

Berman, E. (2003). Hamas, Taliban and the Jewish Underground: An economist's view of radical religious militias. NBER Working Paper No. w10004. Available at http://www.ndu.edu/library/docs/Berman.pdf

Berman, E., \& Laitin, D. D. (2005). Hard targets: Theory and evidence on suicide attacks. NBER Working Paper No. 11740.

Berman, E., \& Laitin, D. D. (2008). Religion, terrorism, and public goods: Testing the club model. Journal of Public Economics, 92, 1942-1967.

doi: 10.1016/j.jpubeco.2008.03.007

Berman, E., Felter, J., \& Shapiro, J. N. (November 2009). Do working men rebel? Insurgency and unemployment in Iraq and the Philippines. NBER Working Paper No. w15547.

Berman, E., Shapiro, J. N., \& Felter, J. H. (2011). Can hearts and minds be bought? The economics of counterinsurgency in Iraq. Journal of Political Economy, 119(4), 766-819. doi: 10.1086/661983

Blomberg, S. B., Hess, G. D., \& Weerapana, A. (2004). An economic model of terrorism. Conflict Management and Peace Science, 21(1), 17-28. doi: $10.1080 / 07388940490433882$

Bueno de Mesquita, E. (2005a). Conciliation, counterterrorism, and patterns of terrorist violence. International Organization, 59(1), 145-176. doi: $10.1017 /$ S0020818305050022 
Bueno de Mesquita, E. (2008). The political economy of terrorism: A selective overview of recent work. Available from http://home.uchicago.edu/ bdm/PDF/pe-terror.pdf

Bueno de Mesquita, E. \& Dickson, E. S. (2007). The propaganda of the deed: terrorism, counterterrorism, and mobilization. American Journal of Political Science, 51, 364-381.

Crost, B., \& Johnston, P.B. (November 2010). Aid under fire: Development projects and civil conflict. Belfer Center Discussion Paper, No. 2010-18, Harvard Kennedy School.

Combating Terrorism Center (CTC). (release date: February 14, 2006). Letter to Mullah Mohammed 'Omar from bin Laden. CTC's Harmony Document Database. Retrieved from http://www.ctc.usma.edu/wp-content/uploads/2010/08/AFGP-2002-600321-Trans.pdf

Combating Terrorism Center (CTC). (release date: October 2, 2007a). Bin Laden and Farouq letters. CTC's Harmony Document Database. Retrieved from http://www.ctc.usma.edu/wp-content/uploads/2010/08/AFGP-2002800073-Trans-Meta1.pdf

Combating Terrorism Center (CTC). (release date: October 2, 2007b). Characteristics of Jihad Magazine. CTC's Harmony Document Database. Retrieved from http://www.ctc.usma.edu/wp-content/uploads/2010/08/AFGP2002-600142-Trans-Meta.pdf

Combating Terrorism Center (CTC). (release date: October 2, 2007c). Declaration of jihad against the Americans. CTC's Harmony Document Database. Retrieved from http://www.ctc.usma.edu/wp-content/uploads/2010/08/AFGP- 
2002-003676-Trans-Meta.pdf

Fearon, J. D. (2008). Economic development, insurgency, and civil war. In E. Helpman (Ed.), Institutions and economic performance (pp. 292-328). Cambridge: Harvard University Press.

Frey, B. S., \& Luechinger, S. (November 12th, 2002). How to fight terrorism: Alternatives to deterrence. Zurich IEER Working Paper No. 137. doi: $10.2139 / \operatorname{ssrn} .359824$

Iannaccone, L. R. (1992). Sacrifice and stigma: Reducing free-riding in cults, communes, and other collectives. The Journal of Political Economy, 100, 271-291.

National Consortium for the Study of Terrorism and Responses to Terrorism (START). Global Terrorism Database (GTD) [Data file]. Available from http://www.start.umd.edu/gtd

NATO C3 Agency. Afghanistan Country Stability Picture (ACSP) [Data]. Retrieved from http://gis.nc3a.nato.int/ACSP

Siqueira, K., \& Sandler, T. (2006). Terrorists versus the government: Strategic interaction, support, and sponsorship. Journal of Conflict Resolution, 50, 878-898. doi: 10.1177/0022002706293469

United States Army (2006) Counterinsurgency: Field Manual 3-24. Washington: Government Printing Office.

World Public Opinion. (September 27, 2006). The Iraqi public on the US presence and the future of Iraq. Program on International Policy Attitudes. Retrieved from http://www.worldpublicopinion.org/pipa/pdf/sep06/Iraq_Sep06_rpt.pdf 